DE DE GRUYTER OPEN
Journal of Intercultural Management

Vol. 6, No. 4, December 2014, pp. 69-79

DOI 10.2478/joim-2014-0036

Justyna Starostka*

Akademia Leona Koźmińskiego

\title{
Design and design thinking in building an innovative organizational culture ${ }^{1}$
}

\begin{abstract}
For many companies innovations are crucial for achieving a competitive advantage. Many factors have been revealed to be determinants of company innovativeness. One is organizational culture which can support or diminish innovative attempts of employees. In recent years there is a growing interest in design and design thinking as methods of implementing innovations. Interdisciplinary, multicultural teams, fast prototyping, co-creation with users are only examples of specific methods that are being promoted by designers and design thinkers, that can significantly affect organisational culture.

The objective of this paper is to analyse the impact of design and design thinking on the organizational culture. In the first part literature findings are presented. The second part shows results of the exploratory research that has been conducted among designoriented companies from Sweden and Poland. This project was qualitative study aimed to compare managers' attitudes towards design; to look into existing processes in companies connected with design and to explore the different roles that designers play in organizations.
\end{abstract}

Key words: organizational culture, design management, design thinking, innovations.

\section{Introduction}

Traditionally, design was understood mainly as aesthetics, external form of a product. In recent years, however, we can observe increased interest in design in a much broader sense - as a tool to support the creation of innovation, building

1 This paper is a result of a research project "Alternative sources of social capital in management practices within organizations" run at Kozminski University and funded by National Center for Research and Development in Poland

*jstarostka@kozminski.edu.pl 
strong brand, or even the strategy throughout the organization. Design can benefit company at many levels, one of which is organisational culture. By cooperating with designers and design thinkers company can implement new methods of working, which are based on experimentations, visual thinking, multidisciplinarity and deep user empathy. Many organisations nowadays establish "design alliances" - very close cooperation with design specialists who act like a knowledge brokers, helping companies experiment and innovate continuously.

The objective of this paper is to analyse the impact of design and design thinking on the organizational culture. In the first part of the article we present the literature review on design and design management, then we introduce the concept of organisational culture. In the second part of the article we present some evidence from exploratory research conducted among Swedish and Polish furniture companies. We show some insights on how companies use design and what type of organisational benefits they gain.

\section{The role of design in business}

The role of design has shifted considerably over the past few years. Design is now being recognized as a key business asset that can add significant value to business performance (Press \& Cooper, 2003; Kristensen \& Gronhaug, 2007; Brown, 2009). Traditionally, design was perceived mainly as visual appearance, aesthetics, external form of a product. In recent years, however, we can observe increased interest in design in a much broader sense - as a tool to support the creation of innovation, building strong brand, or even the strategy throughout the organization (Martin, 2009; Verganti, 2006, 2009). Design management has grown to become important business specialization, because, as Bruce and Bessant (2002) put it: 'Good design does not happen by accident, but rather as the result of a managed process'. Borja de Mozota (2003) stresses that design is based on exploration and risk-taking, whilst management is founded on control and predictability, thus design management can present significant challenge to many organizations.

There are many benefits of design for business. In this paper we analyse the three main levels: financial; marketing (product and brand) and organizational.

In the financial area the literature has clearly proven the positive impact of design on a number of financial measures (for example: sales, return on equity, net income, operating cash-flow) and higher share prices of listed companies using design (Hertenstein, Platt \&Veryzer 2005). Design allows to use the strategy of high prices (Borja de Mozota 2006).

In the area of marketing, the main benefits are associated with the product. In the literature we can find the elements such as the creation of more innovative, attractive products that appeal customer's attention (Jerrard \& Hands 2008, Bloch 1995, Creusen \& Schoormans 2005). Design helps to create "visual equity" - a 
situation where products are easily recognizable and distinctive from the competition (Bruce \& Daly 2007). The second perspective within marketing area relates to the brand, and some authors mention: stronger brand identity and positive experiences connected with it. Design works as a form of communication, helps to form a unique perception of the brand, and the appropriate management of design also allows for enhanced, magnified the role of visual elements and greater efficiency of the information provided (Ulrich \& Eppinger 2000, Jerrard \& Hands 2008). The literature emphasizes that design also enhances customer satisfaction and loyalty (Jerrard \& Hands 2008).

The last set of benefits are connected with organisational benefits. In this area design is very often related to organisational change and learning. Some authors see design as an element of change management, where designers can help to adapt to changing market conditions. Utterback notes that designers have three types of knowledge: knowledge of technological possibilities, knowledge about users and knowledge of the products language and that they are able to easily integrate all those three in successful products (2006). Many authors often refer to unique characteristics of companies that cooperates with designers. Some authors call it "design thinking businesses" (Martin 2009, Brown 2008), others call it "design attitude" (Boland, Collopy, Lyytinen \& Yoo 2008), while others refer to it as "design mindset" (Dunne \& Martin 2006). All those are connected with specific competencies of organizations that are actively cooperating with designers. As the main designers' characteristics that are highlighted by researchers are: empathy, integrated thinking, optimism, innate desire to experiment, finding innovative solutions and multidisciplinarity (Brown 2008). It is also stressed that designers have a specific set of practical skills related to the creation of visualizations, prototypes, mock-ups, models, simulations or technical drawings that can support productivity and efficiency. In the area of organizational benefits, design is also treated as a source of process improvement (Bruce \& Cooper 1997, Lockwood 2009). For example during the new product development designers can help to reduce time to market, achieve the user orientation and avoid conflicts (Jerrard \& Hands 2007).

\section{Design thinking}

Precisely because of the specific ways of designers' work and their unique approach to solving design problems, managers started adopting those methods in solving managerial problems. This method is called in the literature "design thinking". One of the most popular advocates of design thinking, Thomas Lockwood defines it as follows: "The term design thinking is generally referred to as applying a designer's sensibility and methods to problem solving, no matter what the problem is. It is not a substitute for professional design or the art and craft of designing, but rather a methodology for innovation and enablement" (Lockwood 2009). 
The design thinking process is called "human-centered" because it starts with the people. It begins by examining the needs, dreams, and behaviours of individuals (Desirability). Once it's identified what is Desirable, the lenses of Feasibility and Viability are brought in. So it is tested (1) what is technically and organizationally feasible (Feasibility) and (2) what can be financially viable? (Viability) (Brown 2009). Many authors focus on specific tools that can be used by managers. Lockwood indicates that design thinking process is using observation, collaboration and rapid concept prototyping as a characteristic points of the method: "Design thinking is a human-centered innovation process that emphasizes observation, collaboration, fast learning, visualization of ideas, rapid concept prototyping, which ultimately influences innovation and business strategy. The objective is to involve consumers, designers, and business people in an integrative process, which can be applied to product, service, and experiences to market" (Lockwood 2009).

There are several key tenets of design thinking that seem to be common (Lockwood 2009; Brown 2009; Martin 2009):

- Deep understanding of the consumer based on emphatic approach (observational and ethnographic methods);

- Collaboration through forming multidisciplinary teams;

- Accelerate learning through visualization, hands-on experimentation, and creating quick prototypes, which are made as simple as possible to get usable feedback;

- Visualization of concepts by using prototypes (concept sketches, physical mockups, stories, role playing) to make intangible become tangible;

- Concurrent business analysis integrated during the process rather than added on later.

Design thinking helps companies to discover and exploitation of new business opportunities. Martin (2009) emphasises that companies need to understand and balance the exploitation and exploration processes. At the same time, he indicates that still very few companies can actually do this successfully (he calls those companies "design-thinking businesses").

\section{Design in the organisational culture}

Organizational culture can be defined as the values, beliefs and hidden assumptions that organizational members have in common (Cameron and Quinn, 1999; Deshpande and Webster, 1989; Miron et al., 2004). Various researchers have proven that culture plays very crucial role in innovation processes (Higgins and McAllaster, 2002; Jassawalla and Sashittal, 2002; Martins and Terblanche, 2003). Tesluk et al. (1997) argue that culture have a dual effect on innovation - from the viewpoints of socialization and of co-ordination. Through socialization, individuals can know whether creative and innovative behaviours are part of the path the business treads. At the same time, the business can, through activities, policies and procedures, gen- 
erate values, which support creativity and innovation, and its innovative capacity will subsequently improve (Naranjo-Valencia, Jimenez-Jimenez \& Sanz-Valle 2011).

There are many models that distinguish different organisational cultures using different criteria. Cameron and Quinn (1999) proposed a model called Competing Values Framework that defines four cultures - adhocracy, clan, market and hierarchy. This model uses two dimensions. The first dimention is flexibility and discretion versus stability and control, the second - external focus versus internal focus and integration. We can discuss that, by having external, user focus and using and having the mind-set oriented on constant experimentation, design and design thinking can help companies to move towards adhocracy. And that type of culture is necessary for companies that want to innovate, as adhocracy cultures foster innovation strategies and hierarchical cultures promote rather imitation (NaranjoValencia, Jimenez-Jimenez \& Sanz-Valle 2011).

Even if the literature on organizational change is rich and heterogeneous, only a few contributions have discussed the idea that design culture and practice can be a vehicle, an agent of change in the culture of an enterprise. Buchanan argues for a new kind of design research, oriented directly toward the influence of design on organizational life (Buchanan, 2008). Junginger examines the possibility that product development might lead to organizational change in an enterprise when it is bound to the idea that the process of product development should be "human-centered," and thus provoke "outside-in" change, as opposed to the normal "inside-out" view of the organization as a machine (Junginger, 2007). However the process can be characterized by tensions, conflicts and misunderstandings. As Deserti and Rizzo stress: "Designing significantly new products might bring unexpected changes in the culture of an enterprise because contradictions might arise between the current culture and the one needed to implement the innovations. Thus, when design culture interacts with the culture of an enterprise (...) the culture of the enterprise might change as an unexpected consequence of the interaction between the two types of culture".(2013, p. 36). The analysis of design from the perspective of organizational change throws new light on the relationship between design culture and enterprise culture, as design challenges the natural organizational attitudes of preservation and resistance to change. That can generate a constant tension between the search for innovation and the necessity of relying on established ideas and solutions. This constant tension builds a significant link between design practice and culture and the problem of managing organizational change (Deserti \& Rizzo, 2013, p. 42).

The problems described above make it worthwhile to ask what are the differentiating factors of organizations in which the design is a success from those that are not successful in this field. "Good design is good business" - a phrase uttered by Tom Watson in 1975, is one of the most cited quotes related to design. This phrase suggests that the employment of the designer brings immediate results and always 
successful. However, it is known that this is incorrect thinking - collaboration with designer does not immediately means success, and a lot depends on the company and people within the organisation (Moore 2004). According to the literature first key success factor is the conviction of the management company of the value of design (Bruce \& Bessant 2002, Kotchka 2003, Sanches 2006). The involvement of senior management is crucial because it provides the necessary resources, the full involvement of the company in issues related to the design (Lockwood 2004). The second factor distinguished by some authors is the multidisciplinarity (Roy \& Potter 1993, Bruce \& Bessant 2002). The creation of an appropriate structure for the exchange of information and climate based on the cooperation is an essential prerequisite for success. It is important to integrate design with different areas within the organisation and create a culture of collaboration, teamwork, flexible problem solving (Hart \& Service 1988, Sanches 2006). The third factor is timely introduction of the designer in the process of developing a new product (Bruce $\&$ Bessant 2002). It is emphasized that the earlier involvement, the greater the chances for a comprehensive development of the idea of a new product (Sanches 2006).

Having all that in mind we try to explore how introducing design and design thinking projects can affect the organizational culture of enterprise.

\section{Research methodology}

In the second part of this article we present results of the exploratory research project. Objective of this study was to empirically explore the nature of the current role of design within design-oriented companies ('design leaders') from Sweden and Poland. This project was qualitative research aimed to compare managers' attitudes towards design; to look into existing processes in companies connected with design issues and to explore the different roles that designers play in organizations.

We've decided to narrow our study only to 'design leaders' in order to identify and compare best practices in both countries. In the process of selecting those companies, the following criteria have been taken into account: number of design awards ('Red Dot Design Award', 'The Design S' in Sweden and 'Dobry Wzór' in Poland), industry publications, consultations with design specialists and designers, companies' web pages.

In this research project 24 in-depth interviews were conducted among two groups of respondents: marketing managers/CEOs and designers. Interviews were carried out over a period of six months (from January to July 2010). Interviews were guided by a semi-structured questionnaire, ranged from one to two hours, were taped and transcribed. The broad themes of the questionnaire encompassed the following: company and respondent characteristics, attitudes towards design, design management, processes and strategies connected with design, the role of designer 
in a company and design-marketing interplay. In the next section we present briefly the results of our study. Company names are omitted for confidentiality reasons.

\section{Design as a way for building an innovative organisation - empirical examples}

Most of the interviewees agreed that design is now an essential tool for managing a company; a tool that improves functioning of the whole organization in different areas. As a result of this approach, designers were playing very important roles. In most cases they were involved in issues that go far beyond the traditional realm of their work. Despite the fact that the companies often worked with external designers, usually with one or more of them they were establishing very close cooperation. Often, these designers were invited to take active part in 'Design Advisory Board' or 'Board Product' meetings, where issues related to the development of new products, new trends, marketing, public relations were being discussed. In this approach, designers acted like brand consultants, advisors, interpreters of market changes. One respondent described this phenomenon as follows:

Most of the companies that strategically approach design, receive help from designers who act like creative directors for these brands. For example, the company $Z$ has XY who is a designer for them, but he is also the unofficial art director of the company... he leads them, advises them, looks at the ideas of others.

Some respondents were highlighting the role of designers in the area of organizational and product innovations. One manager admitted that designers are very often the source of overcoming certain organizational limitations, but sometimes it can presents a significant challenge:

As a producer you have an idea what you can do and you have limitations of what you think you cannot do. And a designer, on the other hand, very often asks you to do something that you think you don't have tools for, and then you can have a fight, conflict. But it's very important to have fresh eyes from outside, so that you don't get stuck on what is limiting you. Very often you don't get the new tools to work out new things, if you're not pushed by designer.

Respondents also emphasized that in recent years, more and more companies have increasingly became "virtual organisations", focusing mainly on designing and building a brand name, outsourcing production to external entities. This change has had a direct impact on expanding the requirements for designers' work. One of them said that today being a designer is like having several different jobs at the same time. He stressed that in order to convince the company to his concept, he often has to create an advertising campaign around his idea, allowing the company to immediately see the additional value of new product. It is also more often required to provide the technological know-how associated with the manufacturing processes or the materials used. Those changes are well illustrated by the following quotation: 
The myth of the designer doing a sketch on a napkin, in a bar somewhere, has nothing to do with reality. Companies now very often don't own production, don't have the knowledge, technological know-how, which means that we [designers] have to go to the sub-contractor to gain this knowledge to sell our idea to the specific company.

As one interviewee said, it's very important that design should be in the interest area of every employee in a company:

Design management is to initiate, to maintain, and to realize creative process. [...] It's not just about that it was your idea, but this project must become a part of the entire company, so that every employee will identify with what you and your team are doing. [...] Every employee should feel somehow a part of this creative design process.

Many of those companies promote flexible ways of looking for new product ideas. They have developed three main ways of the design process: (1) cooperation with architects; (2) product propositions send by designers and (3) 'traditional' design process initiated by the design brief:

During the year, we have constantly new products on the run. Initiatives for those products come from different ways. One way is when an architect is working on a project and have a special product need - so if they have an idea about those products, we build this product together. And that is what we do a lot of times. (...) The second way is that we have this ongoing relation with the designers that we work with and (...) sometimes there is 1, or 2 or 3 that I work with at the same time. And they have lot of ideas what they want to do. The third way is when we feel that we lack product in a specific area. I give them [designers - JS] a brief and tell them that actually I want this type of product.

When asked about the effects on working closely with designers, one manager admitted that:

This experience gave us a lot, not only in this particular project, but like more in general, in the way how we think and start new ventures. Right now we think in terms of the service design really, we try to develop user experience approach and we try to look at everything with different eyes, it is a change of perspective for $u$ s.

As the team managed to implement and execute the idea via design thinking approach, the whole concept of how the organisation was looking for innovation has changed. Other team member was talking that the whole culture of company has changed:

This project was just a beginning of the creation of such a culture based on the design for the client and with the client, so the design-thinking culture. And this was a great positive side of it. Now we have such a situation that different people come to us and report issues and want us to belp them with their projects to be conducted in accordance with the design thinking methodology.

Now the whole unit has developed its own design thinking methodology and works mainly according to this process introduced by design consultancy. As one of the team members said: "We have built greater confidence in ourselves". 


\section{Conclusions}

The aim of this article was to present the role of design and design thinking in building innovative organizational culture. Design culture and practice can be a vehicle, an agent of change in the culture of an enterprise it can be a good starting point of further discussion in this area. By employment of the "human-centered" approach, designers and design thinkers can provoke organizational change to "outside-in", as opposed to the normal "inside-out" view of the organization. As this process may bring tensions and some difficulties, it's crucial to realise the success factors distinguished in the literature: the conviction of the management company of the value of design; multidisciplinarity and timely introduction of the designer in the process of developing a new product. Cooperation with designers and design thinkers can be a starting point of the overall organisational change. Higher risk tolerance, the real customer involvement and earlier concept validations are only a few examples of the long-lasting benefits observed.

As research presented in this article was exploratory in nature we think it can be a good starting point for more in-depth research projects on the role of design and design thinking in building innovative organisational cultures of different types of organisations.

\section{References}

Bloch P.H. (1995), Seeking The Ideal Form: Product Design And Consumer Response, Journal of Marketing, Vol. 95 Issue 3

Boland J., Collopy F., Lyytinen K., Yoo Y. (2008), Managing As Designing: Lessons for Organization Leaders From The Design Practice Of Frank O. Gehry, Design Issues, Vol. 24 Issue 1

Borja de Mozota B. (2006), The Four Powers Of Design: A Value Model In Design Management, Design Management Review, Vol. 17 Issue 2

Brown T. (2008), Design Thinking, Harvard Business Review, Vol. 86 Issue 6

Bruce M., Bessant J. (2002), Design In Business. Strategic Innovation Through Design, Pearson Education Limited, England

Bruce M., Cooper R. (1997), Marketing and Design Management, Thomson Business Press, Cornwell

Bruce M., Daly L. (2007), Design And Marketing Connections: Creating Added Value, Journal of Marketing Management, Vol. 23 No. 9-10

Buchanan, R. (2008). Design and Organizational Change. Design Issues, Vol. 24 No 1.

Cameron, K.S and Quinn, R.E. (1999), Diagnosing and Changing Organizational Culture. Based on the Competing Values Framework, Addison-Wesley, Reading, MA

Creusen M., Schoormans J. (2005), The Different Roles Of Product Appearance In Consumer Choice, Journal of Product Innovation Management, Vol. 22 Issue 1 
Deserti, A., \& Rizzo, F. (2013). Design and the Cultures of Enterprises. Design Issues, Vol. 30 No 1

Deshpande, R. and Webster, F. (1989), Organizational culture and marketing: defining the research agenda, Journal of Marketing, Vol. 53, January

Dunne D., Martin R. (2004), Design Thinking And How It Will Change Management Education: An Interview And Discussion, Academy of Management Learning \& Education, Vol. 5 Issue 4

Hartmann, A. (2006), The role of organizational culture in motivating innovative behaviour in construction firms, Construction Innovation, Vol. 6 No. 3

Hayes R. (1990), Design: Putting Class into 'World Class', Design Management Journal, Vol. 1 Issue 2

Hertenstein J., Platt M., Veryzer R. (2005), The Impact of Industrial Design Effectiveness on Corporate Financial Performance, The Journal of Product Innovation Management, Vol. 22 Issue 1

Jerrard R., Hands D. (2008), Design Management: Exploring Fieldwork and Applications, Routledge, London

Junginger, S. (2007). Product Development as a Vehicle for Organizational Change. Design Issues, Vol. 24 No 1

Kotchka C. (2003), The Design Imperative In Consumer Goods, Design Management Review, Vol. 17 Issue 1

Kristensen, T., Gronhaug K. (2007). Editorial Essay: Can Design Improve The Performance Of Marketing Management?, Journal Of Marketing Management, 23 (9-10)

Lockwood T. (2004), Integrating Design Into Organizational Culture, Design Management Review, Vol. 15 Issue 2

Martin, R. (2009). The Design of Business: Why Design Thinking Is the Next Competitive Advantage, Boston, Mass.: Harvard Business Press

Miron, E., Erez, M. and Naveh, E. (2004), Do personal characteristics and cultural values that promote innovation, quality, and efficiency compete with or complement each other?, Journal of Organizational Behavior, Vol. 25, pp. 175-99

Moore C. (2004), Declaring Victory: Toward A New Value Proposition For Business Design, Design Management Review, Vol. 15 Issue 2

Naranjo-Valencia J., Jiménez-Jiménez D., Sanz-Valle R., (2011), Innovation or imitation? The role of organizational culture, Management Decision, Vol. 49 Issue 1

Press, M., Cooper, R. (2003). The Design Experience: The Role Of Design And Designers In The Twenty-First Century, Ashgate Publishing

Roy R., Potter S. (1993), The Commercial Impacts Of Investment In Design, Design Studies, Vol. 14 Issue 2

Sanches R. (2006), Integrating Design into Strategic Management Processes, Design Management Review, Vol. 17 Issue 4

Service L., Hart S., Baker M. (1989), Profit By Design, Design Council, London 
Tesluk, P.E., Faar, J.L. and Klein, S.R. (1997), Influences of organisational culture and climate on individual creativity, The Journal of Creative Behaviour, Vol. 31 No. 1

Ulrich K., Eppinger S.D. (2000), Product Design And Development, The McGraw/Hill Companies, Boston

Utterback J., Vedin B.A., Alvarez E., Ekman S., Sanderson W., Tether B., Verganti R. (2006), Design-Inspired Innovation, World Scientific Publishing, Singapore

Verganti, R. (2006). Innovating Through Design, Harvard Business Review, Vol. 84 Issue 12, December

Verganti, R. (2009). Design Driven Innovation: Changing the Rules of Competition by Radically Innovating What Things Mean, Harvard Business Press, Boston

Veryzer R., Borja de Mozota B. (2005), The Impact Of User-Oriented Design On New Product Development: An Examination Of Fundamental Relationships, The Journal of Product Innovation Management, Vol. 22 Issue 2. 